\title{
EDUCATION IN THE MODERN URBAN SETTING
}

\author{
Herbert SchuEler ${ }^{*}$
}

There are no problems of our changing urbanized society that have been subject to more debate, that have yielded greater displays of emotion, illogic, intemperance, and self-seeking prejudice, that have more persistently defied well-meaning attempts at solution, be they piecemeal or long range, than the problems of urban education. For there is no privacy in American public education; it is the most cogent example of a major institution created for the people and specifically controlled by them in many interlocking ways from basic policy to day-by-day operation. In part, this is due to the sensitivity of American education through its public-based structure to lay influence; but perhaps in even greater part it is due to a fundamental characteristic of American culture that recognizes the function of the school not only as a reflection but as a developer of society in all its cultural and social aspects. Therefore, we are perhaps more prone than other peoples this side of the Iron Curtain to see in the school a major influence in shaping society as we think it should be shaped. And since there are many people, and many opinions, and since the avenues of influence are many, ranging from legally constituted local and state boards of control to parents associations, from voluntary social, commercial, and political influence groups to textbook publishers, and from civic, religious, and business leaders to the individual parent, the schools are beset on all sides by many voices, carrying varying degrees of authority, varying degrees of reason, opinion, passion, statesmanship, and demagoguery, between them covering the full range of the political, social, and economic spectrum. The dividing line between professional and lay influence in American education fluctuates in direct proportion to the degree of crisis, with lay influences seeking greater impact as the problems of society are felt to be more acute.

When Sputnik I in one dramatic orbit launched the space age, and the first grapefruit-sized American would-be satellite expired miserably just off its launching pad, a chorus of critical voices was raised against the thereby demonstrated "weaknesses" of the American educational system. Yet when many successes a relatively short time later established the United States as a respectable competitor to the Russians in space research (achieved by the very same school generations that had been condemned previously), the blame originally laid to the schools was not changed to praise. In the same way, after Pearl Harbor, cries were heard that socalled "progressive education" had weakened the moral fiber and discipline of the

- B.S. 1934, M.S. 1935, City College, New York City; Ph.D. 1937, New York University. Dircctor of Teacher Education and Chairman, Department of Education, Hunter College of the City University of New York. Author [with Gerald S. Lesser], TeAcher, Education and thre New MEdis (in press, Fall 1964); Associate Editor [with Harry N. Rivlin], Encyclopedia of Modern Education (I943). 
American people, yet when the war was over, its demonstrated affirmation of a people's inventiveness, scientific ingenuity, production capacity, courage, and discipline did not result in paeans of gratitude being sung to the schools. It has been said that the United States has more experts on education than voters, all confident that they know what's wrong.

Yet there is a positive side to this willingness to make a scapegoat out of the American school. The American school has long been accepted as a major social instrument, as a shaper of custom and of a people's ability to think, believe, and achieve along desirable national and local ends. Thus Sputnik unleashed not only criticism, but an unprecedented stimulation and reform of instruction in the sciences and mathematics in the schools as well. American leadership in the United Nations has profoundly influenced social science curricula by giving them a predominantly international flavor, a movement being fought with some success by hyper-nationalistic, isolationist voluntary groups. The Good Neighbor Policy of the New Deal stimulated a widespread growth in the study of Spanish-American and South and Central American culture.

It is completely within the pattern of our culture, therefore, for the schools to be the center of attention in our nation. None of the several presidential messages to the American Congress in January I 65 was launched with such fanfare nor was received with such widespread, detailed comment and analysis as President Johnson's Message on Education. His opening remarks set the theme: "Congress declared in the Northwest Ordinance: 'Schools and the means of education shall forever be encouraged.' America is strong and prosperous and free because for 178 years we have honored that commitment." And his concluding words left no doubt of his conception of the place of the school in our society: ${ }^{1}$

We are now embarked on another venture to put the American dream to work in meeting the new demands of a new day. Once again we must start where men who would improve their society have always known they must begin-with an educational system restudied, reinforced, and revitalized.

And as tangible proof of the magnitude of his administration's commitment, he proposed another $\$$ I.5 billion of federal aid to be added to the \$I.5 billion already appropriated by the Congress. While this sum, if voted, is but a small fraction of the amount allocated to defense, it does represent a quadrupling of federal aid to education over the amount allocated for the previous fiscal year. Editorial comment during the days following echoed the theme of the President's message; in one way or another the schools from the lowest to the highest must shoulder the responsibility of finding solutions to the nation's most pressing social problems, particularly those that have their roots in poverty and social disadvantage. And of these, none are more pervasive in their potential of damage to national well-being in all its

${ }^{1}$ Message from the President of the United States Transmitting Education Program, H.R. Doc. No. 45, 8gth Cong., Ist Sess., $x$, Ix ( 1965$)$. 
aspects, social, economic, and ethical, than the problems engendered by the accelerated urbanization of our society and the spread in our cities of teeming ghettoes of the disadvantaged. Thus, the problems of urban society are mirrored in the urban school; and in times of crisis the school increasingly is expected to bear not only a major share of the blame for the failures of society but the chief responsibility for its improvement.

It is no accident, therefore, that urban civil rights movements are concentrating much of their fire on the schools and on the inequities reflected in de facto segregation, even though housing patterns and not the volition of the school are the primary cause. In no other democratic society has so much faith been vested in the schools as a means of overcoming social injustice and of achieving social ends as our own. To many school people this is a frightening responsibility, particularly when responsibility is suddenly vested without sufficient thought to the human and material resources that are needed but rarely given. Yet in spite of the social naiveté and immaturity that expects miracles of an institution that rarely receives proper subvention except in times of crisis, the fact remains that of all public social agencies, the only one with the necessary stability and support, both in law and substance, and with the public acceptance that can effect social change, is the public school. It is the only public agency that can command directly the major portion of an individual's life for a minimum of ten years of his life span in the critical years of his development to manhood, with the potential of additional influence during his adult years, even if only through his children. In urban and suburban communities, the only established social agency that is within walking distance of every man, woman, and child in the neighborhood is the public school. It enjoys both the sanctions of the law through compulsory education laws and the stability of permanent endowment by means of public funds. It is the one common institution that has the potentiality of exercising its effect on most of the people residing within its ken. While the responsibility may be frightening, particularly to school professionals who find it thrust upon them suddenly and without proper training, on a typically American crash basis, the inescapable conviction is growing that, unless the institution of the public school is deliberately used to overcome the growing social, economic, and cultural impoverishment that is becoming characteristic of our inner cities, very little that is tangible will actually happen-except that the social dynamite that Conant warns of in his Slums and Suburbs ${ }^{2}$ will explode into progressively more delinquency, crime, violence, and despair.

What then are the prospects of finding within education some of the solutions of our growing urban problems?

\section{Problems of De Facto Segregation}

Traditionally, school populations reflect the neighborhoods they serve. The younger the school population, the smaller the school unit and the smaller the

${ }^{2}$ James B. Conant, Slums and Suburbs (rg6r). 
district it serves. In urban tenement areas, therefore, elementary schools are districted in such a way that they serve the immediate neighborhood. The junior high school, on the other hand, being a larger unit, serves a number of elementary school districts; and the high school, being the largest unit of all, serves a number of junior high school districts, if it is of a general, comprehensive nature, and an entire large urban area if it fulfills a specialized, city-wide function. Particularly in the elementary schools the ethnic, social, and economic characteristics of the immediate neighborhood are reflected in the student body. Other things being equal (the effect of parochial and non-sectarian private schools, and the gerrymandering of school districts may introduce complicating factors), an elementary school in a district that is largely Negro and of lower socioeconomic class will have a corresponding proportion of children enrolled who are Negro and of lower socioeconomic class. In the older sections of our urban areas, therefore, de facto ethnic and social class segregation in the elementary schools and to some extent in the junior high schools is the normal consequence of providing school facilities as close as possible to pupils' homes. Housing patterns have been allowed to determine the nature of the school population. With the large scale in-migration of lower socioeconomic minority groups into the older sections of all our urban areas, many of the schools serving these areas have become examples of segregation fully comparable in extent, if not in cause, to schools in the South, and as such the target of civil rights groups.

In fact, no problem of urban education has received as much attention both from civil rights groups of all degrees of militancy and from their opposing forces as has de facto segregation. Demonstrations, picketing, sit-ins, boycotts have been used by both sides in the dispute; and there is a real question whether the resultant hardening of opposing factions has not done more harm than good to the cause of equality of opportunity in education. It is the avowed purpose of one side of the dispute to overcome and negate the effect of housing patterns through deliberate redistricting of schools to achieve a mixing of ethnic and socioeconomic groups in the school population in such a manner that no one minority group represents the majority of a given school population. It is their contention that schools with a predominantly minority group population are by their very nature inferior and psychologically degrading to the disadvantaged youngster. Those who wish to preserve the characteristics of the neighborhood school argue that children should be enrolled in the school closest to their homes so that they will be with their own neighborhood friends both within school and out. There is room for reasoned argument on both sides; unfortunately, as is so often the case when militant extremes are brought into play, there is danger that it will become increasingly difficult for those who agree on basic ends-the furtherance of equality of opportunity in education-but disagree as to the means, to come together in reasoned solutions acceptable to both. There is danger, too, that the effect of the battle may achieve just the opposite purpose of the goals of civil rights groups-the removal 
of large numbers of middle-class, non-minority group children from public schools into private and parochial systems, thereby making desegregation all but impossible. This process is already well under way, for example, in such changing urban areas as the borough of Manhattan in New York City.

Meanwhile many schemes for redistricting and reorganization to achieve greater spread of populations in the schools are being tried and proposed. In that sense, the advocates of desegregation are having greater effect than their opponents. There follows a short summary of the more representative efforts and proposals.

\section{A. Redistricting}

I. Redrawing districts to cut across ethnic and socioeconomic neighborhood population lines. This measure is most effective for schools in so-called fringe areas, but is almost impossible to achieve for schools placed in the centers of large ethnic population centers, like New York City's Harlem, unless the need for large-scale transportation is accepted. Where conscious gerrymandering has been undertaken to preserve the segregated character of a school, a practice unfortunately not unknown in some communities, redistricting would actually make schools more accessible and ethnically better balanced.

2. Building new schools in fringe areas rather than in the centers of ethnic populations. The mobility of inner city populations would in all probability soon negate this measure, requiring further redistricting if the original spread of population is to be maintained.

3. "Open enrollment," or providing opportunities for voluntary transfer of students into schools in other districts, particularly into those that have under-utilized school buildings. This plan has the advantage of not being compulsory for any child, but is limited to available places in under-utilized, receiving schools. In addition, experience has shown that the opportunities for voluntary transfer are seldom fully utilized.

4. School pairing known as the "Princeton Plan," and its variants. Two schools serving contrasting populations are paired in such a way that all the children in the two districts attend one school for the early grades, and the other for the upper grades. This plan is more feasible in fringe areas than in the centers of large ethnic concentrations, unless large-scale transportation of children is undertaken.

5. The school park. This most intriging proposal departs drastically from convention and is at the opposite pole of the neighborhood school concept. It advocates the establishment of clusters of "feeder schools" around large comprehensive secondary schools, thereby creating large school neighborhoods serving the widest possible population. Since these parks would be new, embodying the latest in educational design and program, and in effect would create their own neighborhood, it is hoped that they would not only effectively serve an integrated school population, but overcome the objections of middle-class parents to sending their 
children to school in slum neighborhoods. Aside from the major capital expense involved-they are of the magnitude of urban renewal projects-this plan would involve major transportation problems.

\section{B. Vertical Reorganization}

Under the prevailing 6-3-3 plan of school organization, the smallest unit of the system, the six year elementary school, encompasses the longest age span, and traditionally is zoned on a neighborhood basis. Since arguments for the local neighborhood school have the greatest cogency for young children and the least for adolescents, several plans for vertical reorganization have been proposed which would reduce the age span of the lowest school and increase it for the upper schools, thereby automatically enlarging the geographical spread of population for intermediate and upper age groups. One such plan is the 4-4-4 which would reduce the upper limit of the elementary school to the fourth grade, establish a middle school for grades five through eight, and expand the present three year high school to grades nine through twelve. A variant of this plan, and possibly a first step toward its ultimate adoption is the 5-3-4 announced for implementation in the Fall of 1965 by the New York City Board of Education. This plan adds the former elementary school sixth grade to the junior high school, and the former junior high school ninth grade to the senior high school. Both plans will inevitably serve to reduce somewhat the incidence of de facto segregation in the schools. They are however opening a Pandora's box of program, personnel, and facilities problems that will take some time to solve. By adding a ninth year to already overcrowded urban high schools, the need for additional split sessions and shortened school days will become acute until additional facilities can be built. Similarly, questions of program and personnel remain largely unresolved.

The great danger in all the foregoing plans, which concentrate on reducing de facto segregation by measures that are essentially geographical, is the assumption, implied though rarely stated, that equality of opportunity for all ethnic and socioeconomic levels of urban society will be assured primarily by mixing children in the schools in the proper proportion. The evils of inequality, of bigotry, of prejudice, of unmitigated economic and social disadvantage and of ghetto living are not automatically overcome by making sure that for every Negro and Puerto Rican child there is a mainland middle-class white child in the same school. The special needs of the child reared in poverty and in the culture of dulling despair can go as unrecognized and unfulfilled in the new integrated school as in the segregated old one. Without proper curricula, teachers, guidance, and other auxiliary services created with the specific needs of the disadvantaged student in mind, no effort at desegregation by itself will achieve gains in the direction of equality of opportunity. In fact, it may actually retard its attainment. There is nothing more devastating than failure incurred in the company of those who succeed. 


\section{COMPENSATORY Education}

It should be axiomatic that the way to overcome existing disadvantages is by providing compensatory advantages. Fortunately, the climate seems at last to be favorable for providing the kinds of compensatory measures needed to overcome the deteriorating social conditions in our growing urban centers of population. It is finally being realized that there is no escape from the deprivation and despair which has become characteristic of so many of our central cities unless extraordinary and effective countermeasures are sought and provided. For children born to disadvantage, the major means of escape is through education, without which our increasingly automated and specialized society provides little chance of upper mobility. Yet the incidence of premature school drop-outs is greatest among adolescents in slum areas, as is teen-age and young adult unemployment, and all the consequent ills of deprivation like delinquency, dope addiction, and crime. Nor is any significant proportion of these disadvantaged groups found in the universities, colleges, and vocational institutes where they can develop the skills for entrance into professions and sub-professions that provide the best means for social upper mobility and entrance to positions of leadership in the community. While education can and must provide the answer, it is obviously not yet doing so in sufficient measure to check the spread and hardening into permanent immobility of disadvantaged populations in our cities. What are some of the more promising compensatory measures that are being undertaken and proposed by which education can provide the means of overcoming disadvantage among urban populations?

\section{A. Expanding Schooling to the Early Childhood Years}

Public elementary school education traditionally begins at age six, and the class for six-year-olds is therefore called the first grade. This is the age at which compulsory education laws first apply. Kindergartens for the five-year-olds are provided in most urban school systems on a limited voluntary basis. Nursery schools for children of four and even younger are usually under private auspices.

Many urban school systems are beginning to realize, however, that notable contributions can be made to the optimum development of a child, particularly one being reared in disadvantaged circumstances, if schooling can begin earlier than the age of six. It is becoming increasingly evident through a variety of experiments and developmental studies that very young children can benefit emotionally, socially, and intellectually from properly organized school experiences. For the lower class child being brought up in disadvantaged circumstances, very early schooling can compensate for the lack of emotional security and intellectual stimulation available in his home and neighborhood. It is to be expected, therefore, that the next few years will see a considerable expansion of urban public education downward to ages five and four, particularly in disadvantaged areas. Among the characteristics of these efforts will be the attempt to build parents, guardians, older siblings, and 
adult community volunteers into the program with the help of contacts provided by social workers and visiting teachers, and the exploration of ways to begin at an early age the cognitive development of children so that they will get an early start in the development of basic skills of communications and reading, thereby hopefully precluding much of the need for remedial action later on.

Ultimately, it is expected that the urban school will extend downward to the age of five, and even to the age of four, for all children.

\section{B. Building Curricula Pertinent and Stimulating to the Student}

Learning is an individual, personal process; it takes place to the degree that what is to be learned is within the developing powers of the learner, and to the degree that he feels it to be pertinent, desirable, and necessary for him to learn. Unfortunately, so much of what the lower class, minority group child is expected to learn and the form and manner in which it is presented to him was developed with somebody else in mind. For example, he recognizes few of the people or situations in his basic reader-the characters he encounters there live in suburban, private homes, amid lawns and trees; they have gentle pets and are pals with the milkman; and Daddy comes home every evening in his neatly pressed suit with a briefcase under his arm. He sees little relationship between his life, his interests, his home, and the life that enfolds before him in his textbooks. Little that he is asked to learn seems of much use to him. The curriculum is about other people, others' lives; and he neither has nor can have any particular desire to understand it, much less learn from it. Not only his books but also his teachers are of that other world with which he can find no kinship.

No learning can take place without continuing reference to the state of the learner-his feelings, his motivations, his experiences, his life style. In the case of the disadvantaged urban child, the problem is complicated by the material and psychic handicap he carries with him by virtue of his disadvantage, and by the minimal help he can be expected to receive-more often the handicaps that will beset him-from his own environment as he attempts to find his way in that most middle-class, bourgeois of institutions, the school.

The problem, therefore, of devising a program of schooling designed to bring the disadvantaged child from where he is to the level to which he can and should aspire is an exceedingly complex one. It requires for its base an intimate knowledge of the culture of his environment, of his innate capabilities, and of the legitimate aspirations toward which he can be motivated. It requires materials and procedures for learning that are adapted to his apperceptive environment and that he can be taught to accept as pertinent and worthwhile to his own development. Of course, this is true of any learner-the advantaged as well as the disadvantaged. The trouble is that so little of what has been done in the urban schools has grown out of this knowledge; so little of the curricula and procedures have been pertinent to what 
is fast becoming in every urban school system in the nation the majority population of the public schools. The task ahead is a major one, and while many beginnings have been made-cultural enrichment programs ("Higher Horizons"), reading texts with content communicable to the urban child, work-study programs for teen-agers, talent discovery programs departing from reliance on standardized tests that are culturally unfair to children of minority groups, all-day neighborhood school programs providing stimulation and enrichment otherwise absent in neighborhood and home, and so on-by far the major effort is still ahead.

It is encouraging, therefore, that the President's 1965 message on education urged first priority and the greater part of augmented federal aid to be devoted to bringing "better education to millions of disadvantaged youth who need it most." Such a program will need considerable financial subsidy from state and federal sources, since the needs are far beyond the taxing power of the cities themselves. Above all, it will need dedicated professionals in large numbers trained to act in different and more effective ways.

\section{Providing Expanded Auxiliary Services}

The necessary greater individualization in the schooling of disadvantaged youth will require not only smaller class size and more teacher time for each learner, but augmented auxiliary services as well. For direct assistance to both children and teachers, trained guidance counselors, psychologists, consulting psychiatrists, nurses, and social workers are needed. In response to the need for knowledge of home and neighborhood environment, and for building positive home-school relationships, the development of a new type of professional has been suggested-the school social worker, whose training and function would combine pertinent elements of both teaching and social work.

It is no longer possible "just" to teach reading, mathematics, and foreign languages. The old progressive slogan "to teach the whole child" is no longer merely a slogan; it has again been restored to professional respectability. The disadvantaged youngster cannot be expected to find the proper guides, models, and motivations in his own environment; they must be provided by the school. To be sure, with proper coordination of effort (as yet rarely found in our cities) between schools and settlement houses, welfare agencies, religious bodies, youth boards, and the police, some of the increased need can be met with the help of auxiliary agencies; but a considerable augmenting of these services within the school will still be found necessary.

\section{Extending the School into the Community}

The primary effect of a school on the community is through the children it serves. In addition, it can, and indeed should, provide services to adults. Any school in a thickly populated urban area that is dark in the evening is a tragically unused resource. Under proper supervision, it can provide greatly needed recrea- 
tional, vocational, educational, and advisory services to the community at large as well as to the children of school age.

A fine example is the community school movement at Flint, Michigan, one of many such developments in expanding industrial urban areas. For a mere seven per cent addition to the normal school budget, Flint keeps all its schools open to eleven o'clock at night and on Saturdays for a wide variety of informal and formal community uses-from opportunities to drop in for a chat and a cup of coffee in the "community room" to a course in home management on a tight budget. As community centers these schools have become focal points for positive elements in an urban, industrial community to spread their influence, and they have served to raise measurably the morale of even the most deprived of neighborhoods.

\section{E. Developing Skilled Teachers and Counselors}

The key to solutions of the problems of urban education is the teacher. It is he who deals directly and personally with the object of all education, the student. And with youngsters who find a dearth of models and guides to look up in their own environment, the teacher's function of acting in loco parentis takes on a new and deeper meaning. In the teacher are centered the basic resources of compensatory education which the disadvantaged child needs to overcome the deprivation of his environment. The teacher needs to be resourceful, sympathetic, firm, and dedicated to his functions and his mission. He must be able to communicate at a level of workable empathy with his students. And above all, he needs to find sufficient satisfaction in his position so that he will resist the temptation of moving to wealthier, better paying suburban schools.

Unfortunately, the problem of recruiting good teachers for inner city schools remains acute. Many refuse to serve, others leave after a short, unsatisfying, frustrating period of service, and still others remain at a level of demeaning performance that is not much better than providing custodial discipline. Fortunately, the level of performance and the dedication of many who have remained provide clues for more effective programs of recruitment and training.

It has been demonstrated in a sufficient number of pilot programs that effective and satisfied teachers can be recruited and trained for service with disadvantaged youngsters. Several programs conducted by units of City University of New York have gone far beyond the pilot stage and have incorporated the goal of preparation of inner city urban service into their regular teacher education programs.

If this goal of recruitment and preparation for urban teaching is accepted, teacher education programs will inevitably find themselves faced with the hard, pragmatic necessity of training not for the ideal but for the real, not for the abstract, generalized classroom that is supposed to be typical of all, but for the one that exists in Junior High School I7; not for teaching that mythical being, the Child, but John, José Maria; not for a school that exists somewhere, and therefore actually nowhere, but 
the one that serves an actual neighborhood with all its uniqueness. It means further that greater emphasis will have to placed on possible contributions of disciplines heretofore largely lacking in programs of teacher education-sociology, cultural anthropology, social psychology-particularly as they can contribute to an understanding of the dynamics of urban life. It means finally that much greater emphasis than ever before will have to be placed on continuing on-the-job training that will assist the teacher to acquire those specific facets of knowing, doing, and being that will make him effective in the unique situation in which he is expected to serve.

The teacher needs to be helped to understand the background of his students, the physical and psychological enviroment in which they are growing up. He needs to develop and refine his adaptive skills in providing and guiding learning experiences appropriate to his students. Finally, and most crucially, he needs to understand, and as far as possible influence, the way in which he himself affects the attitudes and behavior of the young people in his charge. All these imperatives are complicated by the fact that the teacher of the inner city school is rarely of the same social or economic class as his students. For the foreseeable future, few teachers will emerge from the ghettoes of the inner city. The opportunities for the talented and the gifted among the disadvantaged to benefit from the higher education that is needed in preparation for professional service are as yet too few; far too few survive even the compulsory schooling age. The teacher will therefore need his own kind of compensatory education, one that will make up for his lack of living, or having lived, in the environment of his students.

These training needs will require close coordination between schools and training colleges. Neither can function effectively alone. For the colleges it will mean, in addition to the establishment of realistic training programs, bringing major human and material resources to bear on programs of study, research, and consultative services geared to assist the schools to achieve improved functioning within the inner city communities. For the schools it will mean a recognition of the imperative of providing, with the help of universities, continuing on-the-job training and of making it possible for teachers to gain personal contentment in their difficult positions by providing the services and the help and the recognition they need.

\section{F. Developing Centers of Demonstration, Training, and Research}

A natural consequence of this need for pragmatic study, training, and school improvement is the growing movement to establish in the cities centers of demonstration, training, and research that are quite unlike the university-sponsored "model" of campus schools of another day, dealing as they do with population, problems, and necessities as they are found in the public school as it actually exists. These centers are taking a wide variety of forms, some quite informal and casual in nature, others specifically organized for research and demonstration purposes. In one way 
or another, however, they involve some kind of school-university partnership and serve to provide both laboratory experiences for pre-service and in-service training programs for teachers and facilities for research and demonstration intended to improve school programs.

It is expected, however, that the President's $x^{9} 65$ Message on Education and the subsequent stimulation of massive federal and foundation aid will serve to bring such centers to the fore as large-scale, well-endowed operations, particularly in densely populated urban areas where they are needed most. As outlined in the President's message, such centers would not only provide facilities for research, demonstration, and training, but would provide supplementary resources to students with special needs that cannot be provided in each individual school.

\section{G. Coordination of Efforts of Educational and Social Service Agencies Serving the Same Community}

There are many public and voluntary agencies in most urban communities. While the need requires much more effort than has yet been exerted, there is danger, as more resources are found, that by the uncoordinated proliferation of effort on the part of many agencies the social gain may actually decrease as more effort is expended.

As the school is expected more and more to concern itself with the community it serves, as it accepts its responsibility of dealing with the child in his total environment, it will need all the assistance it can get from related professionals serving the same community. Unfortunately much still needs to be done to build even elementary channels of communication among the many agencies that are working on different but complementary aspects of the same problems. It is possible, more likely probable, that one can find many examples in the city of a social investigator, a local minister, a settlement house recreational worker, a youth board volunteer, and a teacher all working with the same child and his family in complete ignorance of one another. It may be that, as this broadened concept of the school's functions finds acceptance, the school in the urban community can become the instrument to achieve this necessary coordination. It has the advantage of already being there, of having facilities already on hand and supported, and of ready access through its students and its program to the majority of people in its service area.

\section{H. Expansion of Low-Cost Educational Opportunities Beyond the Compulsory Schooling Age}

Even if by massive improvement of the school program a much larger proportion of disadvantaged adolescents attain eligibility for higher education than is now the case, very few more would find their way to the colleges and universities unless the economic barriers to higher education for the lower income classes were drastically lowered. Even massive expansion of low-cost federal assistance programs 
to "needy" students will serve to assist only a fraction of those needing help, and hardly at all the lowest income levels. While loans, scholarships, and work-study programs are all helpful, they serve only to emphasize the one great barrier to equal opportunity in higher education that characterizes our society-the almost universal expectation that the student help pay for his higher education through tuition fees. Not until higher education is supported on a basis comparable to the public schools, as are very few systems of higher education in the United States (the nine components of the City University of New York are a prominent exception), will the opportunity for higher education to the lowest income groups begin to approach the need. This means not only the kind of support that will provide free tuition in existing institutions, but a manyfold expansion of facilities for publicly supported higher education serving particularly the urban student.

Unless such opportunity is provided on a massive scale, upper mobility among the disadvantaged groups in our urban society will be seriously inhibited. It will mean an acceleration of the process, already well under way, of establishing a cemented social class structure, at least for the lowest socioeconomic groups. It will mean that what is fast becoming the majority population in our inner cities will be prevented more and more from contributing its legitimate share to the educated leadership of our nation. That way lies disaster!

\section{CONCLUSION}

The problems, therefore, of urban education are many and often discouraging to the point of despair. Its prospects will depend on how and with what kind of support its role, not just as a mirror of the problems of society but as instrument of social change, will be undertaken. It is obviously not the only potentially effective force toward social betterment in the urban community, but very little can be achieved without its help.

\section{REFERENCES}

B. J. Chandler, Lindley J. Stiles \& E. Krtznae (Eds.), Education in URban Soctety (1964). Clark, Clash of Culture in the Classroom, Integrated Education, Aug. 1963, p. 7 .

JaMies B. Consnt, Slums and Suburbs (196r).

Martin P. Deutsch, Minority Groups and Class Status as Related to Social and Personality Factors in Scholastic Achinvement (Society for Applied Anthropology, Ithaca, N.Y., Monograph No. 2, I960).

Educational Policies Commission, Education and the Disadvantaged American (National Education Ass'n, 1962).

Fielding, De Facto Segregation, NEA Journal, May I964, p. II.

Fisher, The De Facto Issue: Notes on a Broader Context, 65 TeAchers College Record 490 (1964).

Dorothy M. Fraser, Deciding What to Teach (NEA, 1963).

Goldberg, Adapting Teacher Style to Pupil Differences, Merrill-Palmer Quar,, April r964.

Handlin, Is Integration the Answer?, Atlantic Monthly, March I964, p. 49.

Havighurst, Metropolitan Development and the Edrcational System, 69 Scrool Rev. 25I (196r).

Hobart, Underachievement Among Minority Group Students, 24 Phylon 84 (1963).

Special issue on "Toward Integration of Northern Schools," 36 J. Educ. SocroLocy 24t-96 (I963).

Special Journal Feature on the Disadvantaged, NEA Journal, April 1963. 
Keppel, Fundamentals in the Battle for Desegregation, Phi Delta Kappan, Sept. 1964, pp. 3-5.

Klineberg, Life Is Fun in a Smiling Fair-Skinned World, Saturday Review, Feb. 16, 1963, pp. 75-77, 87. GoRdon J. KILOPF \& ISRAEL A. LASTER (EDs.), INTEgRATING THE URBAN SchDOL (I963).

Harry L. Miller \& Marjorie B. Smiley, Education and the Metropolis: A Book of Readings (I964). Newton, The Culturally Deprived Child in Our Verbal Schools, 3 J. Negro Educ. I82-87 (1962).

N.Y. City Board of Education, Higher Horizons Progress Report (ig63).

Harry Passow (Ed.), Education in Depressed Areas (1963).

Special Issue on the Culturally Deprived Urban Child, Phi Delta Kappan, Nov. 1963.

Frank Reissman, The Culturally Deprived Child (Ig62).

Taylor, The Whole Child: $A$ Fresh Look, Educational Supplement, Saturday Review, Dec. ro, rg6r, pp. 42-43.

U.S. Commission on Civil Rights, Civil Rights, U.S.A. (Publtc Schools Cittes in the Norte and WEST, 1962) (1963).

U.S. Dep't of Health, Education, and Welfare, Programs for the Educationally Disadvantaged $(1963)$.

Wolfe, Curriculum Adaptations for the Culturally Deprived, 31 J. Negro Educ. 139-5I (1962).

Wrightstone, Demonstration Guidance Project in New York City, 30 Harv. Educ. Rev. 235-5I (I960). 